Pacific Journal of Mathematics

FIXED POINTS ON FLAG MANIFOLDS 


\section{FIXED POINTS ON FLAG MANIFOLDS}

\section{Henry H. Glover and William D. Homer}

When $K$ is $\boldsymbol{R}, \boldsymbol{C}$, or $\boldsymbol{H}$, let $U_{K}(n)$ denote the group of $n \times n$ orthogonal, unitary, or symplectic matrices, respectively. If $G$ is a closed connected subgroup of $U_{K}(n)$ of maximal rank, then it is conjugate to a subgroup of the form $U_{K}\left(n_{1}\right) \times U_{K}\left(n_{2}\right) \times \cdots \times U_{K}\left(n_{k}\right)$. A simple condition on the integers $n_{i}$ is shown to be necessary for $U_{K}(n) / G$ to have the fixed point property (that every self map has a fixed point). It is conjectured that this condition is also sufficient, and a proof is given for some cases.

For a partition $n=n_{1}+n_{2}+\cdots+n_{k}$ of a positive integer $n$ and $K=\boldsymbol{R}, \boldsymbol{C}$, or $\boldsymbol{H}$, the corresponding generalized flag manifold $U_{K}(n) /\left(U_{K}\left(n_{1}\right) \times \cdots \times U_{K}\left(n_{k}\right)\right)$ will be denoted $K M\left(n_{1}, \cdots, n_{k}\right)$. We conjecture that $K M\left(n_{1}, \cdots, n_{k}\right)$ has the fixed point property if and only if $n_{1}, \cdots, n_{l}$ are distinct integers and, when $K=\boldsymbol{R}$ or $\boldsymbol{C}$, at most one is odd. We prove that this condition is necessary and that it is sufficient, in addition to previously known cases, for the manifolds $K M\left(1, n_{2}, n_{3}\right)$ where $n_{3}$ is large relative to $n_{2}$ (and, when $K=\boldsymbol{R}$, in some other cases as well).

THEOREM 1. If $K M\left(n_{1}, n_{2}, \cdots, n_{k}\right)$ has the fixed point property, then $n_{1}, \cdots, n_{k}$ are distinct integers and, if $K=\boldsymbol{R}$ or $\boldsymbol{C}$, at most one is odd.

Proof. We can regard $M=\boldsymbol{C M}\left(n_{1}, \cdots, n_{k}\right)$ as the space of orthogonal direct sum decompositions $C^{n}=V_{1} \oplus \cdots \oplus V_{k}$, where $V_{m}$ has dimension $n_{m}$ over $C$. If $n_{r}=n_{s}$, interchanging the $r$ th and $s$ th summands defines a fixed point free self map of $M$.

For the rest of the proof, we define a conjugate linear transformation $J$ of $C^{n}$ and consider the associated self map $f$ of $M$, which takes $V_{1} \oplus \cdots \oplus V_{k}$ to $J V_{1} \oplus \cdots \oplus J V_{k}$. If $n=2 m$, we regard $\boldsymbol{C}^{n}$ as $\boldsymbol{H}^{m}$ and take $J$ to be multiplication by the quaternion $j$. Any subspace of $\boldsymbol{C}^{n}$ invariant under $J$ has the structure of a vector space over $\boldsymbol{H}$ and so has even dimension as a vector space over $\boldsymbol{C}$. Thus if at least one (and so necessarily at least two) of the integers $n_{1}, \cdots, n_{k}$ is odd, $f$ has no fixed points.

If $n=2 m+1$, we write $\boldsymbol{C}^{n}=\boldsymbol{H}^{m} \oplus \boldsymbol{C}$ and take $J$ to be multiplication by $j$ on the first summand and complex conjugation on the second. If $W$ is a subspace of $\boldsymbol{C}^{n}$ which is invariant under $J$, then its projection onto the first summand is invariant under multiplication by $j$ and so has even dimension over $\boldsymbol{C}$. Hence each odd 
dimensional subspace which is invariant under $J$ must contain the second summand. If at least two of $n_{1}, \cdots, n_{k}$ are odd, it follows that $f$ again has no fixed points.

The proof in the real case is analogous. In the quaternionic case we can construct only the self maps which interchange summands of equal dimensions.

Conjecture 2. The converse of 1 is also true: If $n_{1}, \cdots, n_{k}$ are distinct positive integers and, when $K=\boldsymbol{R}$ or $C$, at most one is odd, then $K M\left(n_{1}, \cdots, n_{k}\right)$ has the fixed point property.

This is well known to be true for complex projective spaces $\left(k=2\right.$ and $\left.n_{1}=1\right)$ and has been proved for many Grassmann manifolds $\left(k=2\right.$ and either $n_{1} \leqq 3$ or $\left.n_{2} \geqq 2 n_{1}^{2}-n_{1}-1[5,3]\right)$. Here we verify the following additional cases.

THEOREM 3. If $n_{2}$ and $n_{3}$ are distinct positive even integers and $n_{2} \geqq 2 n_{2}^{2}-1$, then $C M\left(1, n_{2}, n_{3}\right)$ has the fixed point property.

Proof. Under these hypotheses, Theorem 1.4 of [4] states that every graded ring endomorphism of $H^{*}\left(\boldsymbol{C M}\left(1, n_{2}, n_{3}\right) ; \boldsymbol{Z}\right)$ takes one of two simple forms, termed grading and projective endomorphisms. It suffices to check that for neither type can the Lefschetz number be zero if both $n_{2}$ and $n_{3}$ are even. This will follow from the general results 4 and 5 below.

Recall that the grading endomorphism $\varphi$ of degree $\lambda \in \boldsymbol{Z}$ has the form $\varphi(x)=\lambda^{m} x$ for $x \in H^{2 m}\left(\boldsymbol{C M}\left(n_{1}, \cdots, n_{k}\right) ; \boldsymbol{Z}\right)$.

Proposition 4. A grading endomorphism of $H^{*}\left(\boldsymbol{C M}\left(n_{1}, \cdots, n_{k}\right) ; \boldsymbol{Z}\right)$ has Lefschetz number zero if and only if its degree is -1 and at least two of $n_{1}, \cdots, n_{k}$ are odd.

Proof. Since the Lefschetz number is congruent to 1 modulo the degree $\lambda$ and is positive if $\lambda=1$, it can be zero only if $\lambda=-1$. From [1], the Poincaré polynomial for $C M\left(n_{1}, \cdots, n_{k}\right)$ is

$$
\prod_{j=1}^{n}\left(1-t^{2 j}\right) / \prod_{i=1}^{k} \prod_{j=1}^{n_{i}}\left(1-t^{2 j}\right) \text {. }
$$

The Lefschetz number of the grading endomorphism of degree -1 is the value of this polynomial when $t^{2}=-1$. This value is zero if and only if the number of factors of the form $1-t^{4 j}$ in the numerator exceeds the number of such factors in the denominator, which in turn happens precisely when at least two of $n_{1}, \cdots, n_{k}$ are odd. 
Recall that a projective endomorphism of $H^{*}\left(\boldsymbol{C M}\left(1, n_{2}, \cdots, n_{k}\right) ; \boldsymbol{Z}\right)$ is an endomorphism which factors through the monomorphism induced by the canonical map $\pi: C M\left(1, n_{2}, \cdots, n_{k}\right) \rightarrow C M(1, n-1)=$ $C P(n-1)$.

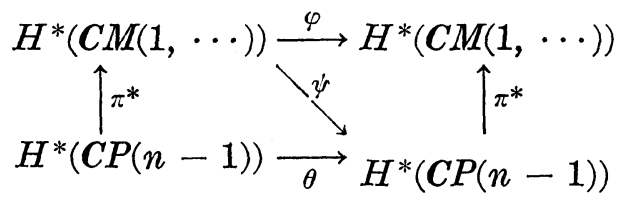

If $\varphi$ factors as $\pi^{*} \circ \psi$, we define its degree to be that of $\theta=\psi \circ \pi^{*}$. Since the Lefschetz number of $\varphi$ equals that of $\theta$, we have the following results.

Proposition 5. A projective endomorphism of $H^{*}\left(\boldsymbol{C M}\left(1, n_{2}, \cdots, n_{k}\right) ; \boldsymbol{Z}\right)$ has Lefschetz number zero if and only if its degree is -1 and $n-1=n_{2} \cdots+n_{k}$ is odd.

The statements for the quaternionic and real flag manifolds are as follows.

THEOREM 6. If $1, n_{2}$, and $n_{3}$ are distinct positive integers and $n_{3} \geqq 2 n_{2}^{2}-1$, then $\boldsymbol{H} M\left(1, n_{2}, n_{3}\right)$ has the fixed point property.

The proof of 6 is analogous to that for 3, with one additional observation. A degree -1 endomorphism (either grading or projective) of cohomology does not commute with reduced third power operations (cf. [2]) and so cannot be induced by a self map.

THEOREM 7. (i) If $n_{2}<n_{3}$ are even integers greater than 1 and either $n_{2} \leqq 6$ or $n_{3} \geqq n_{2}^{2}-2 n_{2}-2$, then $R M\left(1, n_{2}, n_{3}\right)$ has the fixed point property.

(ii) If $n_{1}, n_{2}$, and $n_{3}$ are positive integers such that at most one is odd, $n_{1} \leqq 3, n_{3} \geqq n_{2}^{2}-1$, and $\left[n_{1} / 2\right]<\left[n_{2} / 2\right]<\left[n_{3} / 2\right]$, then $\boldsymbol{R} M\left(n_{1}, n_{2}, n_{3}\right)$ has the fixed point property. (Here $[r]$ denotes the greatest integer in $r$.)

Proof. Since at most one of $n_{1}, n_{2}$ and $n_{3}$ is odd, $O\left(n_{1}\right) \times O\left(n_{2}\right) \times$ $O\left(n_{3}\right)$ has maximal rank in $O(n)$. It follows that $H^{*}\left(\boldsymbol{R} M\left(n_{1}, n_{2}, n_{3}\right) ; \boldsymbol{Q}\right)$ is generated as an algebra by the Pontryagin classes of the canonical $n_{i}$-plane bundles (cf. [1]). To simplify notation, let $\bar{m}$ denote [m/2].

Ad (i): If $n_{1}=1$, then $H^{*}\left(\boldsymbol{R} M\left(1, n_{2}, n_{3}\right) ; \boldsymbol{Q}\right)$ is isomorphic as a graded algebra (with a shift in the grading) to $H^{*}\left(\boldsymbol{C} M\left(\bar{n}_{2}, \bar{n}_{3}\right) ; \boldsymbol{Q}\right)$. Since $n_{2}$ and $n_{3}$ are distinct even integers, $\bar{n}_{2}$ and $\bar{n}_{3}$ are distinct. 
By Theorem 1 of [3] (with the slight improvement noted in [4]), $H^{*}\left(\boldsymbol{C} M\left(\bar{n}_{2}, \bar{n}_{3}\right) ; \boldsymbol{Q}\right)$ admits only grading endomorphisms when either $\bar{n}_{2} \leqq 3$ or $\bar{n}_{3} \geqq 2 \bar{n}_{2}^{2}-2 \bar{n}_{2}-1$, which are equivalent to the inequalities in the statement of (i). The grading endomorphism of degree -1 has Lefschetz number 0 when $\bar{n}_{2}$ and $\bar{n}_{3}$ are both odd. But suppose $f$ is a self map which takes the first two rational Pontryagin classes $p_{1}$ and $p_{2}$ of the canonical $n_{2}$-plane bundle over $\operatorname{RM}\left(1, n_{2}, n_{3}\right)$ to $-p_{1}$ and $p_{2}$ respectively. Then for the mod 3 Pontryagin classes we also have $f^{*}\left(\widetilde{p}_{1}\right)=-\widetilde{p}_{1}$ and $f^{*}\left(\widetilde{p}_{2}\right)=\widetilde{p}_{2}$. The splitting principle (Proposition 25.4 of [1]) and the Cartan formula imply that the reduced third power operation $\mathscr{P}^{1}$ takes $\widetilde{p}_{1}$ to $2\left(\widetilde{p}_{1}^{2}+\widetilde{p}_{2}\right)$, so we have

$$
\begin{aligned}
& \mathscr{P}^{1} \circ f^{*}\left(\widetilde{p}_{1}\right)=\mathscr{P}^{1}\left(-\widetilde{p}_{1}\right)=-2\left(\widetilde{p}_{1}^{2}+\widetilde{p}_{2}\right)
\end{aligned}
$$

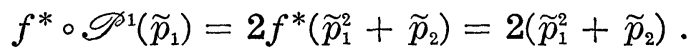

Hence no such $f$ exists, and so every self map of $R M\left(1, n_{2}, n_{3}\right)$ has nonzero Lefschetz number. (Note that this corrects the proof of Theorem 5 in [3], where $\widetilde{p}_{2}$ was inadvertently omitted from the formula for $\mathscr{P}^{1}\left(\widetilde{p}_{1}\right)$.)

Ad (ii): If $n_{1}=2$ or 3 , then $H^{*}\left(\boldsymbol{R} M\left(n_{1}, n_{2}, n_{3}\right) ; \boldsymbol{Q}\right)$ is isomorphic (with a shift in grading) to $H^{*}\left(\boldsymbol{C} M\left(1, \bar{n}_{2}, \bar{n}_{3}\right) ; \boldsymbol{Q}\right)$. We proceed as in the proof of (i), with Theorem 1.4 of [4] restricting the possibilities for cohomology endomorphisms and a similar $\mathscr{P}^{1}$ argument to show that the projective endomorphism of degree -1 (which has Lefschetz number 0 if $\bar{n}_{2}+\bar{n}_{3}$ is odd) is not realized by a self map.

\section{REFERENCES}

1. A. Borel, Topics in the homology theory of fibre bundles, Lecture Notes in Mathematics, 36 (1967), Springer-Verlag.

2. E. Fadell, Recent results in the fixed point theory of continuous maps, Bull. Amer. Math. Soc., 76 (1970), 10-29.

3. H. Glover and W. Homer, Endomorphisms of the cohomology ring of finite Grassmann manifolds, Proceedings of the Northwestern University Conference on Geometric Applica. tions of Homotopy Theory, Lecture Notes in Mathematics, 657 (1978), Springer.Verlag, 170-193.

4. - Self maps of flag manifolds, Trans. Amer. Math. Soc., 267 (1981), 423-434.

5. L. O'Neill, The fixed point property for Grassmann manifolds, Ph. D. Dissertation (1974), The Ohio State University.

Received May 22, 1981 and in revised form July 29, 1981.

Ohio State University

Columbus, OH 43210

AND

Memorial University

St. John's, Newfoundland A1B 3X7 


\section{PACIFIC JOURNAL OF MATHEMATICS}

\section{EDITORS}

DONALD BABBITT (Managing Editor)

University of California

Los Angeles, CA 90024

Hugo Rossi

University of Utah

Salt Lake City, UT 84112

C. C. MOore and Arthur Agus

University of California

Berkeley, CA 94720
J. DugundJI

Department of Mathematics

University of Southern California

Los Angeles, CA 90007

R. FinN and J. MILGRAM

Stanford University

Stanford, CA 94305

\section{ASSOCIATE EDITORS}
R. ARENS
E. F, BECKENBACH
B. H. NeumanN
F. WOLF
K. YoSHIDA

\section{SUPPORTING INSTITUTIONS}

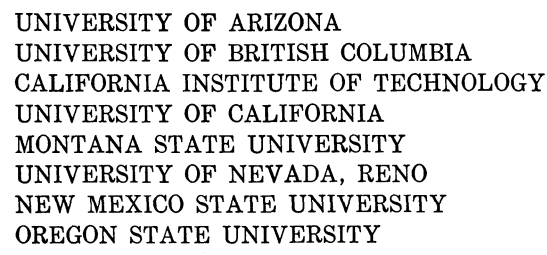

UNIVERSITY OF ARIZONA

UNIVERSITY OF BRITISH COLUMBIA

CALIFORNIA INSTITUTE OF TECHNOLOGY

UNIVERSITY OF CALIFORNIA

MONTANA STATE UNIVERSITY

UNIVERSITY OF NEVADA, RENO

NEW MEXICO STATE UNIVERSITY

OREGON STATE UNIVERSITY

\author{
UNIVERSITY OF OREGON \\ UNIVERSITY OF SOUTHERN CALIFORNIA \\ STANFORD UNIVERSITY \\ UNIVERSITY OF AAWAII \\ UNIVERSITY OF TOKYO \\ UNIVERSITY OF UTAH \\ WASHINGTON STATE UNIVERSITY \\ UNIVERSITY OF WASHINGTON
}

The Supporting Institutions listed above contribute to the cost of publication of this Journal, but they are not owners or publishers and have no responsibility for its content or policies,

Mathematical parers intended for publication in the Pacific Journal of Mathematics should be in typed form or offset-reproduced, (not dittoed), double spaced with large margins. Please do not use built up fractions in the text of the manuscript. However, you may use them in the displayed equations. Underline Greek letters in red, German in green, and script in blue. The first paragraph or two must be capable of being used separately as a synopsis of the entire paper. Please propose a heading for the odd unmbered pages of less than 35 characters. Manuscripts, in triplicate, may be sent to any one of the editors. Please classify according to the scheme of Math. Reviews, Index to Vol. 39. Supply name and address of author to whom proofs should be sent. All other communications should be addressed to the managing editor, or Elaine Barth, University of California, Los Angeles, California, 90024.

50 reprints to each author are provided free for each article, only if page charges have been substantially paid. Additional copies may be obtained at cost in multiples of 50 .

The Pacific Journal of Mathematics is issued monthly as of January 1966, Regular subscription rate: $\$ 114.00$ a year $(6$ Vol., 12 issues). Special rate: $\$ 57.00$ a year to individual members of supporting institution.

Subscriptions, orders for numbers issued in the last three calendar years, and changes of address shoud be sent to Pacific Journal of Mathematics, P.O. Box 969, Carmel Valley, CA 93924, U.S.A. Old back numbers obtainable from Kraus Periodicals Co., Route 100, Millwood, NY 10546.

PUBLISHED BY PACIFIC JOURNAL OF MATHEMATICS, A NON-PROFIT CORPORATION

Printed at Kokusai Bunken Insatsusha (International Academic Printing Co., Ltd.). 8-8, 3-chome, Takadanobaba, Shinjuku-ku, Tokyo 160, Japan.

Copyright (C) 1982 by Pacific Journal of Mathematics Manufactured and first issued in Japan 


\section{Pacific Journal of Mathematics}

\section{Vol. 101, No. 2 December, 1982}

Jean Bourgain, A Hausdorff-Young inequality for $B$-convex Banach

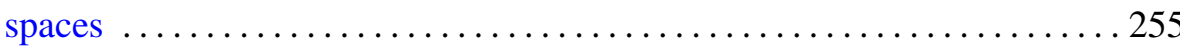

J. L. Brenner and Lorraine L. Foster, Exponential Diophantine

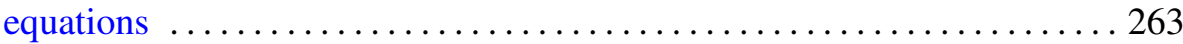

Henry H. Glover and William Duncan Homer, II, Fixed points on flag

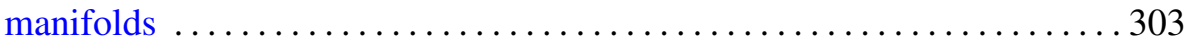

Lothar Hahn, A note on stochastic methods in connection with approximation theorems for positive linear operators $\ldots \ldots \ldots \ldots \ldots . \ldots 307$

James P. Henderson, Approximating cellular maps between low-dimensional polyhedra

V. K. Jain, Certain transformations of basic hypergeometric series and their

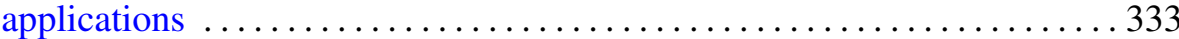

Charles David Keys, On the decomposition of reducible principal series

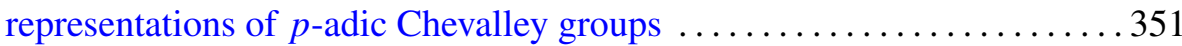

M. S. Klamkin and A. Meir, Ptolemy's inequality, chordal metric,

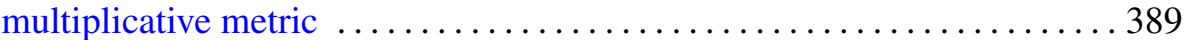

Robert F. Lax, Independence of normal Weierstrass points under

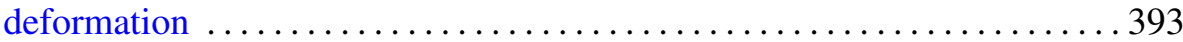

Leonid A. Luxemburg, On compactifications of metric spaces with

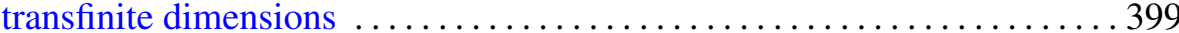

Carlton James Maxson, Martin Ross Pettet and Kirby C. Smith, On semisimple rings that are centralizer near-rings .....

Teodor C. Przymusiński, Extending functions from products with a metric factor and absolutes

Giorgio Talenti, A note on the Gauss curvature of harmonic and minimal surfaces

D. M. Terlinden, A spectral containment theorem analogous to the semigroup theory result $e^{t \sigma(A)} \subseteq \sigma\left(e^{t A}\right)$ 